\title{
Non-Syncytium-Inducing HIV Type 1 Isolated from Infected Individuals Replicates in MT-2 Cells
}

\author{
SERENE E. FORTE, KEVIN S. BYRON, JOHN L. SULLIVAN, and MOHAN SOMASUNDARAN
}

\begin{abstract}
Human immunodeficiency virus type 1 (HIV-1) isolates from six infected individuals less then 4 years of age were phenotyped for their syncytium-inducing (SI) ability in MT-2 cells. Three viral isolates that induced syncytia were detected. One SI isolate was from an individual who was in disease stage P2A,B,C and two SI isolates were recovered sequentially from another individual who switched from disease stage P1B to P2F. Nonsyncytium-inducing (NSI) isolates were detected in two individuals who were in stage P1B of disease, and in a third individual who was in stage P2A of disease. Three sequential isolates obtained over a 2-year period from a fourth individual who progressed from disease stage P1B to P2A,B,C and subsequently died of AIDS-related disease were also found to have the NSI phenotype. To test whether NSI isolates can replicate in the absence of syncytium formation, we analyzed NSI-infected MT-2 cells for production of viral p24 antigen and expression of viral RNA by in situ hybridization. By day 12 postinfection, 6 of 7 NSI viral isolates produced 7- to 36-fold increases in p24 antigen compared to day 6, and expressed viral RNA in 13-20\% of cells. A single NSI isolate that did not replicate in MT-2 cells was obtained from an individual who was asymptomatic (stage P1B). The individual rapidly progressed to symptomatic stage $\mathbf{P 2 F}$ and two sequential SI viruses were isolated. These SI isolates replicated in MT-2 cells and induced cytopathic effects. These results suggest that some cytopathic viral isolates replicate in MT-2 cells in the absence of syncytium induction and replication in MT-2 cells may serve as an indicator for disease progression in certain HIV-infected individuals.
\end{abstract}

\section{INTRODUCTION}

$\mathbf{T}$ HE MECHANISM OF PATHOGENESIS underlying progression to AIDS in HIV-1-infected individuals is largely unknown. It is, however, well documented that steady depletion of CD4 T cells is associated with progressive immunodeficiency. ${ }^{1}$ Although CD4 T cell counts serve as markers for disease progression, ${ }^{2,3}$ the mechanisms of CD4 T cell depletion have yet to be identified. Syncytium formation, single-cell death following high viral load, and apoptosis are a few of the many mechanisms proposed for $\mathrm{CD} 4 \mathrm{~T}$ cell lysis. ${ }^{4-6}$ Studies investigating the course of HIV-1 infection in seropositive individuals clearly suggest that a progressive increase in viral load correlates with emergence of AIDS. ${ }^{7}$ Remarkably, during this period, there are major changes in the biological phenotype of viral isolates. ${ }^{8,9}$

One of the prominent characteristics of viruses isolated during the latter stages of AIDS is their cytopathic phenotype. ${ }^{10}$ The syncytium-inducing (SI) ability of viral isolates in susceptible cells also changes with the switch from asymptomatic to symptomatic disease state..$^{8,11,12}$ Thus, earlier in infection the predominant species of virus is noncytopathic and nonsyncytium inducing (NSI). With the onset of AIDS, viral isolates are cytopathic and SI. The emergence of SI variants also correlates with immunological and clinical deterioration of infected individuals, progressing toward full-blown AIDS. ${ }^{13,14}$ Therefore, along with CD4 T cell counts, the appearance of the SI phenotype has been used as a marker for disease progression. ${ }^{11}$

A highly permissive T cell line (MT-2 cells) that is susceptible to syncytium formation is used to differentiate NSI vs. SI phenotypes in vitro. ${ }^{9}$ Further analyses of HIV-1 and MT-2 cell interactions reveal that syncytia in MT-2 cells are a product of viral replication and that NSI phenotypes do not infect and/or replicate in MT-2 cells. ${ }^{15,16}$

We are investigating mechanisms of HIV-induced cytopathicity and CD4 T cell depletion. To this end, adult and pediatric viral isolates have been phenotyped with regard to their syncytium-inducing ability in MT-2 cells. Unexpectedly, we

Department of Pediatrics, Program in Molecular Medicine, University of Massachusetts Medical School, 373 Plantation Street, Worcester, Massachusetts 01605. 
observed that NSI viral isolates from four of five pediatric patients replicated to high titer in MT-2 cells, as measured by p24 antigen production and in situ viral RNA expression. One infected individual died of AIDS at 18 months of age following a dramatic decline in CD4 $\mathrm{T}$ cell counts. Three sequential isolates from this individual (obtained at 2, 6, and 18 months of age) replicated in MT-2 cells; yet none of these viral isolates (presumably cytopathic in vivo) induced syncytia in MT- 2 cells. We report here that the ability of viral isolates to replicate in MT-2 cells does not always correlate with their respective NSI or SI phenotype. Viral isolates recovered from HIV-1-infected infants with near-normal or low CD4 T cell counts replicated in MT-2 cells regardless of phenotype. In summary, we have shown that HIV-1 isolates replicate in MT-2 cells in the absence of syncytium induction and that progressive immune deficiency occurs in vivo in patients who do not have SI viral isolates.

\section{MATERIALS AND METHODS}

\section{Patients}

Six HIV-1-positive pediatric patients less than 4 years of age were studied with respect to biological phenotype of their viral isolates. Absolute CD4 T cell counts of these children ranged from 64 to $3015 \mathrm{~s} / \mathrm{mm}^{3}$. Clinical stages of the disease for each individual are presented in Table 1.

\section{Isolation and titration of virus}

Virus from each infected individual was isolated by coculture with phytohemagglutinin (PHA)-stimulated normal seronegative donor peripheral blood lymphocytes (PBLs) according to the AIDS Clinical Trial Group (ACTG) Virology Reference Laboratory (VRL) protocol ${ }^{17}$. Patient viral isolates were titered by limiting dilution on PHA-stimulated normal seronegative donor PBLs. ${ }^{18}$ The titers of individual viral isolates are presented in Table 1.

\section{MT-2 cells}

MT-2 cells are human T cell leukemia cells. These were obtained from the AIDS Research and Reference Reagent Program (Cat. No. 237; Bethesda, MD) and propagated in RPMI 1640 containing $10 \%$ fetal bovine serum.

\section{Detection of syncytium-inducing HIV-1 isolates}

Syncytium-inducing HIV-1 isolates were detected using the standardized protocol formulated by the ACTG Virology Committee. ${ }^{8,9,19}$ Titered stocks of patient viral isolates $(50 \mu \mathrm{l})$ were used to infect quadruplicate microcultures of MT-2 cells $\left(5 \times 10^{4}\right)$ in wells of 96-well tissue culture plates containing a $200-\mu$ f final volume. Positive controls were set up using titered laboratory stocks of HIV-1 (50\% tissue culture infective dose $\left[\mathrm{TCID}_{50}\right] / 50 \mu \mathrm{l}=32,750$ ). Negative controls were either unamended medium, or culture supernatant containing a pol-defective, noninfectious NL4-3 HIV-1 strain derived from the $8 \mathrm{E} 5$ cell line. ${ }^{20}$ Plates were incubated at $37^{\circ} \mathrm{C}\left(5 \% \mathrm{CO}_{2}\right)$. Every third day the wells were examined for syncytia, the cell suspension in each well mixed, and $130 \mu \mathrm{l}$ of the cell suspension discarded and replaced with $150 \mu \mathrm{l}$ of fresh medium. On day 14 the assay was terminated and the phenotype of each viral stock was recorded. If three to five "balloons" or giant cells were detected per well under high-power field, the cell culture was scored as positive for syncytia and the phenotype of the viral isolate was recorded as SI. A viral isolate that did not induce syncytia in MT-2 cell culture was phenotyped as NSI. In case of discordant results among quadruplicate wells of a viral stock, the assay was repeated for that particular virus.

\section{Determination of viral replication: Enzyme-linked immunosorbent assay (ELISA) to detect $H I V-1$ p2 $4^{g a g}$ protein}

To follow viral replication in MT-2 cells, cell-free culture supernatants taken every third day at the time of medium ex-

Table 1. Age, Disease Stage, CD4 T Cell Counts of HiV-1-Infected Patients, and Syncytium-Inducing and RePlication Abilities of Viral IsOlates from These INDiViduals

\begin{tabular}{|c|c|c|c|c|c|c|c|c|c|c|}
\hline \multirow[b]{2}{*}{ Patient } & \multirow{2}{*}{$\begin{array}{c}\text { Age } \\
\text { (months) }\end{array}$} & \multirow{2}{*}{$\begin{array}{c}\text { Stage } \\
\text { of disease }\end{array}$} & \multirow{2}{*}{$\begin{array}{c}C D 4 \\
\text { count } / \mathrm{mm}^{3}\end{array}$} & \multirow{2}{*}{$\begin{array}{l}\text { Viral } \\
\text { isolate }\end{array}$} & \multirow{2}{*}{$\begin{array}{c}\text { Titer } \\
\left(T C I D_{50} / 50 \mu l\right) \\
\end{array}$} & \multirow{2}{*}{$\begin{array}{c}\text { MT-2 } \\
\text { phenotype }\end{array}$} & \multicolumn{2}{|c|}{$p 24(n g / m l)$} & \multicolumn{2}{|c|}{$\begin{array}{c}\% H I V-1 R N A \\
\text { positive } \\
\text { (by ISH) }\end{array}$} \\
\hline & & & & & & & Day 6 & Day 12 & Day 6 & Day 14 \\
\hline A & 47 & P1B & 2,312 & A & 2,050 & NSI & 7.5 & 61.5 & 5 & 20 \\
\hline B & 13 & P2A & 2,242 & B & 20,600 & NSI & 8.4 & 166.3 & ND & ND \\
\hline \multirow[t]{2}{*}{$\mathrm{C}$} & 1 & P1B & 2,091 & $\mathrm{C} 1$ & 32,750 & NSI & ND & 195.0 & 6 & ND \\
\hline & 7 & P1B & 2,541 & $\mathrm{C} 2$ & 32,750 & NSI & 5.8 & 57.2 & ND & ND \\
\hline \multirow[t]{2}{*}{ D } & 36 & P2A,C & 64 & D1 & 20,620 & SI & 44.8 & 2,029 & 97 & 70 \\
\hline & 48 & $\mathrm{P} 2 \mathrm{~A}, \mathrm{~B}, \mathrm{C}$ & 8 & D2 & 30 & SI & 29.8 & 2,042 & ND & ND \\
\hline \multirow[t]{3}{*}{$E$} & 2 & P1B & 3,015 & $\mathrm{E} 1$ & 128 & NSI & 2.2 & 14.3 & ND & ND \\
\hline & 6 & P1A & 1,231 & $\mathrm{E} 2$ & 510 & NSI & 10.9 & 364.7 & 9 & 20 \\
\hline & 18 & $\mathrm{P} 2 \mathrm{~A}, \mathrm{~B}, \mathrm{C}$ & 171 & E3 & 51 & NSI & 4.3 & 41.0 & ND & ND \\
\hline \multirow[t]{3}{*}{$\mathrm{F}$} & 3 & P1B & 1,370 & F1 & 320 & NSI & 109.6 & 6.8 & ND & ND \\
\hline & 10 & $\mathrm{P} 2 \mathrm{~F}$ & 1,826 & F2 & 5,160 & SI & 133.9 & 348.0 & ND & ND \\
\hline & 12 & $\mathrm{P} 2 \mathrm{~F}$ & 2,402 & F3 & 5,160 & SI & 125.4 & 217.9 & ND & ND \\
\hline
\end{tabular}

${ }^{a}$ Classification of HIV-1 infection in children under 13 years of age as described by Centers for Disease Control (Atlanta, GA). Abbreviations: ISH, in situ hybridization; SI, syncytium-inducing; NSI, nonsyncytium inducing; ND, not done. 
change from each of quadruplicate wells were assayed for HIV-1 p24 ${ }^{g a g}$ protein using an antigen capture ELISA (Coulter Immunology, Hialeah, FL) according to manufacturer instructions. In our assay, culture supernatants were considered to be positive for HIV-1 when the levels of p24 protein were $\geq 30$ $\mathrm{pg} / \mathrm{ml}$. Steady increases in cell-free $\mathrm{p} 24$ protein levels with time indicated active viral replication in cells.

\section{Determination of viral replication: In situ hybridization to detect HIV-1 RNA in MT-2 cells}

A sample of infected cells was washed with phosphatebuffered saline (PBS), air dried on microscope slides, and fixed in $4 \%$ paraformaldehyde for $10 \mathrm{~min}$ at room temperature. The slides were rinsed in PBS and stored at $4^{\circ} \mathrm{C}$ in $70 \%$ ethanol. At the time of assay, cells were rehydrated and HIV-1 RNA was detected by in situ hybridization according to a previously described method. ${ }^{21}$ A nick-translated, biotin-labeled full-length (8.9-kb) pHXB-2 HIV-1 DNA specific for HIV-1 genomic or mRNA transcripts was used as the probe. Avidin-labeled alkaline phosphatase was used as the marker to detect the biotinylated probe. ${ }^{21}$

\section{RESULTS}

Phenotypes of pediatric viral isolates from seropositive individuals were determined from syncytial assays on MT-2 cells. The positive and negative controls in the MT-2 syncytial assays were normal in all assays. Table 1 describes clinical status, CD4 T cell counts, and SI/NSI phenotype of viral isolates and their corresponding titers from each patient.

Patient isolate $\mathrm{C} 1$ did not induce syncytia in MT-2 cells and was therefore phenotyped as NSI (Table 1); as was a second isolate $\mathrm{C} 2$ from the same individual 6 months later (Table 1). During this period, the individual remained clinically asymptomatic (P1B) and the CD4 T cell counts of this individual did not change dramatically (2091 and 2541; Table 1). Viral isolates from patients A and B had an NSI phenotype (Fig. 1B). Clinically, these patients were classified as P1B (mild) and P2A (mild) and their CD4 T cell counts were 2312 and 2242 (Table 1).

Viral isolates D1 and D2, derived 1 year apart from patient $D$, both induced syncytia in MT-2 cells and were, therefore, determined as SI (Fig. 1C, Table 1). Patient D was clinically classified as P2A,C (mild) with a CD4 T cell count of $64 / \mathrm{mm}^{3}$ and 1 year later had progressed clinically to stage P2A,B,C (severe), with a CD4 T cell count of 8 (Table 1).

Sequential viral isolates were obtained from patient $\mathrm{E}$ over a 16-month period. The first isolate, E1, did not induce syncytia (NSI) and was obtained when the individual was asymptomatic (stage P1B) with a CD4 T cell count of 3015. Within the following year, the patient progressed rapidly to stage P2A,B,C and the CD4 T cell count had dropped to 171. During this period two viral isolates (E2 and E3) remained NSI (Table 1). Although the viral isolate remained NSI, the patient died a few months later.

To determine whether the SI/NSI phenotype of viral isolates correlated with their ability to infect and/or replicate in MT-2 cells, we assayed for the production of HIV-1 p248ag protein and expression of viral RNA. By day 6 of MT-2 syncytial as- says, high levels of HIV-1 p24 were detected in the cell-free supernatants of cultures infected with NSI isolates from patients A, C (isolate C1), and E (isolate E2). The levels of p24 steadily increased and by day 12 the culture supernatants were determined to contain 7- to 36-fold higher levels of HIV-1 p24gag protein (Table 1). Increasing levels of HIV-1 p24 (50- to 75-fold) were also found in cultures infected with SI isolates from patient D (isolates D1 and D2; Table 1).

To confirm active viral replication in MT-2 cells infected with NSI isolates from patients A and E (isolate E2), HIV-1 RNA expression was determined by in situ hybridization (ISH). Viral RNA was detected in MT-2 cells infected with viral isolates from patients $A$ and $E$ (isolate E2; Fig. 2B-E). In cultures of MT-2 cells infected with the NSI isolate of patient A, cells staining positive for HIV-1 RNA increased from $2 \%$ (day 3 ) to $5 \%$ (day 6 ). By day 14 , when the MT-2 syncytial assay was terminated, $20 \%$ of the cells were positive for HIV-1 RNA by ISH (Table 1). Similarly, 9\% of MT-2 cells infected with an NSI isolate from patient $\mathrm{E}$ (isolate E2) were positive for viral expression; by day $14,20 \%$ of the cells were positive for viral RNA (Table 1). The number of cells expressing HIV-1 RNA in cultures of MT-2 cells infected with the SI isolate of patient D

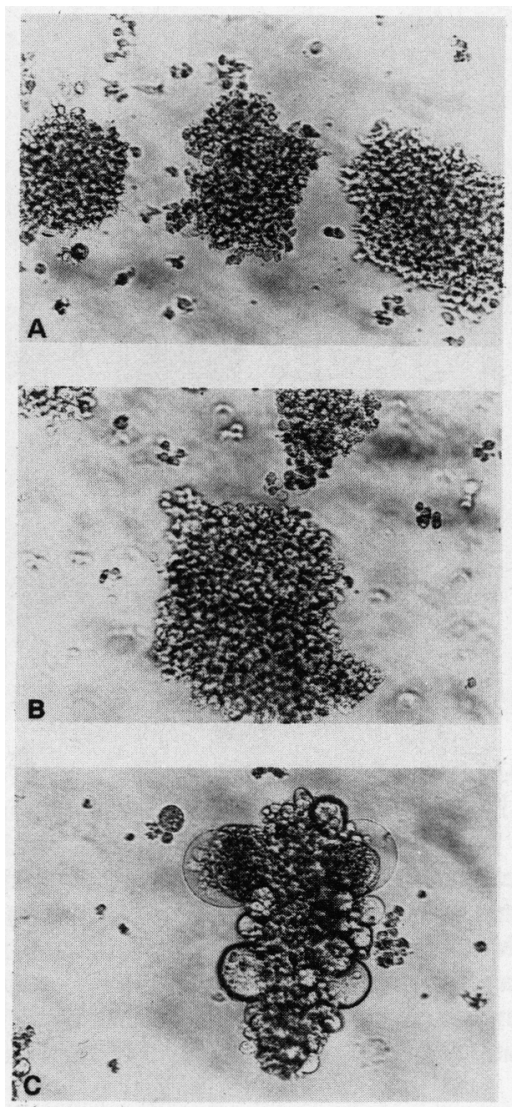

FIG. 1. Phenotype (NSI/SI) of viral isolates from HIV-1infected patients: The NSI/SI phenotype of viral isolates was determined by a syncytial assay using MT-2 cells. ${ }^{8,9,19}$ Shown here is a representative field from cultures of MT-2 cells alone (A), and MT-2 cells infected with an NSI isolate from patient A (B) or an SI isolate, D2, from patient $\mathrm{D}(\mathrm{C})$. 


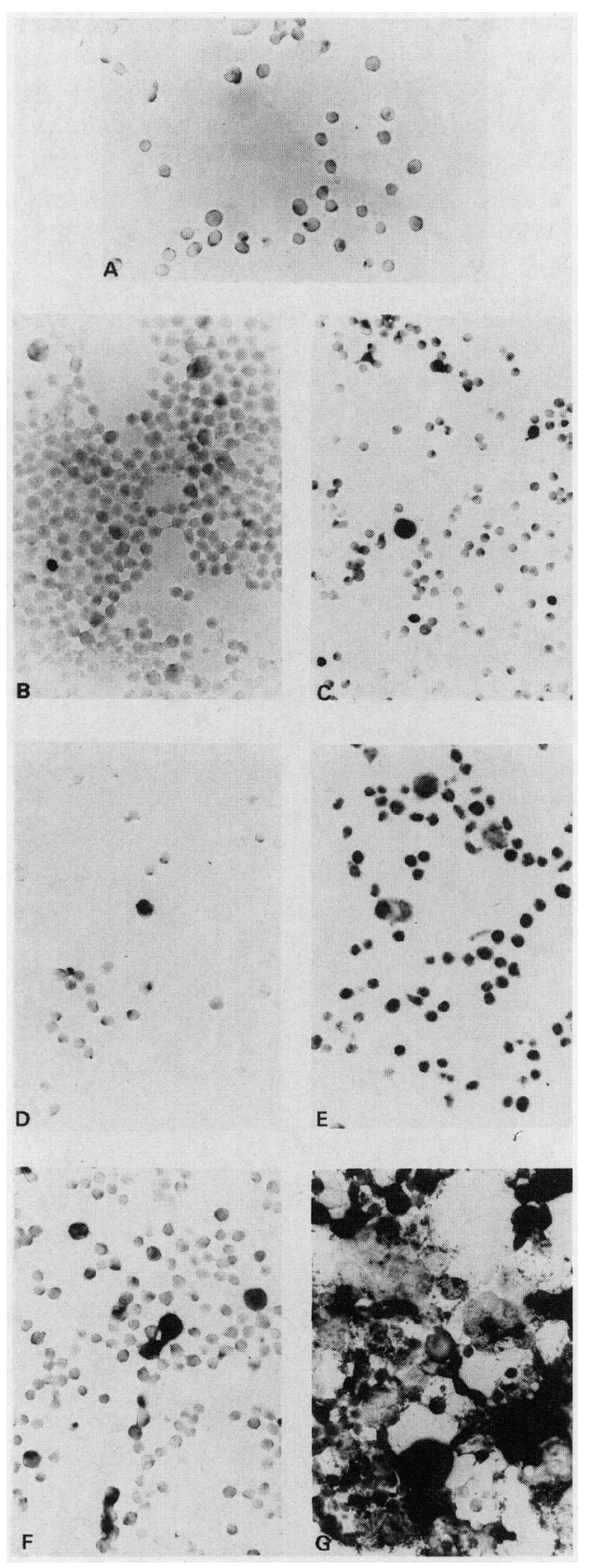

FIG. 2. Detection of HIV-1 RNA-expressing MT-2 cells infected with NSI or SI viral isolates from infected individuals: MT-2 cells were infected with patient HIV-1 isolates. Viral RNA was detected by in situ hybridization using a biotinylated, nick-translated whole HIV-1 DNA genome as probe. ${ }^{21}$ Uninfected MT-2 cells (A); cells infected with NSI isolate from patient A, day 3 (B) and day 6 (C); cells infected with NSI isolate, E2, from patient E, day 3 (D) and day $6(\mathrm{E})$; cells infected with SI isolate, D2, from patient $D$, day $3(F)$ and day $6(G)$.

(isolate D1) ranged from $12 \%$ on day 3 to $>90 \%$ by day 6 (Table 1, and Fig. 2F and G).

The variation in phenotypic pattern of viral isolates from patient $\mathrm{F}$ was similar to that reported for adult patients. ${ }^{15}$ At the early asymptomatic stage of disease (P1B) the phenotype of the viral isolate was NSI. Within a period of 12 months, two sequential isolates derived from patient F showed SI phenotypes. The individual progressed from asymptomatic stage P1B to symptomatic stage P2F during this period but a dramatic decline in CD4 $\mathrm{T}$ cell count was not observed. Levels of viral p24 production in MT-2 cells infected with either of the two SI isolates (F2 and F3) increased whereas p24 levels did not increase in cells infected with the NSI isolate (F1; Table 1).

The syncytium-inducing ability of patient viral isolates in MT-2 cells was not dependent on the amount of viral inoculum (Table 1). Patient isolates with relatively high titer (e.g., isolates $\mathrm{C1}$ and $\mathrm{C} 2$ ) were NSI and did not induce syncytia in MT-2 cells. Viral isolates B and D1 had similar inoculum titers $\left(\mathrm{TCID}_{50} / 50 \mu \mathrm{l}=\sim 20,600\right.$ ) but showed opposite phenotypes in MT-2 cells: isolate B was NSI and isolate D1 was SI. Viral isolate D2 was SI in MT-2 cells. However, viral isolate A was NSI even though the initial inoculum of isolate $A$ was $>64$ fold higher in titer than that of isolate D2. The replicative ability of viral isolates in MT-2 cells was also independent of the inoculum titer. Syncytium-inducing viral isolates F2 and F3 replicated two- to threefold in MT-2 cells between days 6 and 12 of infection. Each of these isolates had an initial titer of 5160 $\mathrm{TCID}_{50} / 50 \mu \mathrm{l}$. However, NSI isolates E2 $\left(\mathrm{TCID}_{50} / 50 \mu \mathrm{l}=510\right)$ and E3 $\left(\mathrm{TCID}_{50} / 50 \mu \mathrm{l}=51\right)$ with lower titers than SI isolates replicated 30 - and 10-fold, respectively, in MT- 2 cells between days 6 and 12 of infection.

\section{DISCUSSION}

In this article we have determined the phenotype of pediatric HIV-1 isolates with respect to their ability to induce syncytia in MT-2 cell cultures. Earlier reports have suggested that SI viruses can productively replicate in MT-2 cells whereas NSI viral isolates cannot. ${ }^{8,9,22}$ Contrary to these reports, we have observed that pediatric patient isolates with the NSI phenotype readily infect and replicate in MT-2 cells. A steady increase in the levels of HIV-1 p $^{\text {gag }}$ protein was observed in cultures of MT-2 cells infected with NSI isolates from patients A, B, C, and $E$. The levels of p24 in these cultures varied from 7- to 36-fold higher than the input levels. By comparison, cultures infected with SI viral isolates contained levels of p24 approximately 60 -fold higher than the inoculum. This suggested that p24 protein detected in the culture supernatants of MT-2 cells infected with NSI or SI isolates was not derived from the initial inoculum but resulted from active viral replication in MT-2 cells. In addition to the detection of HIV-1 p24gag protein levels, we used in situ hybridization to detect active replication in MT-2 cells. The percentage of MT-2 cells expressing HIV-1 RNA in cultures infected with SI or NSI isolates increased from undetectable to $>90 \%$ and $>20 \%$, respectively. These data confirm that, like SI isolates, NSI isolates can productively replicate in MT-2 cells.

We have also observed that the ability to replicate in MT-2 cells and to induce syncytia was independent of the titer of the initial viral inoculum. We have identified pediatric viral isolates that replicate in MT-2 cells in the absence of syncytium formation despite their titer being $10^{3}$-fold higher than a replicating, SI isolate. Furthermore, NSI isolates retained their phenotype when MT-2 cells were either infected with 20 -fold more of the 
NSI viral inoculum or the infected cells were maintained for 28 days, twice the time period the ACTG protocol ${ }^{19}$ called for (data not shown).

Of further interest to us were the cytopathic properties associated with NSI and SI phenotypes. It has been proposed that syncytium formation plays a major role in in vivo $\mathrm{CD} 4 \mathrm{~T}$ cell depletion and HIV cytopathicity. ${ }^{4}$ The NSI phenotype has been associated with lack of clinical progression in seropositive, asymptomatic individuals who have relatively healthy immune systems and high CD4 counts. During the latter stages of disease, when CD4 counts dramatically drop and the immune system deteriorates, SI strains become the predominant phenotype in vivo. ${ }^{10}$ This has led to the hypothesis that SI variants are relatively more cytopathic than NSI variants because of their ability to induce syncytia. ${ }^{8}$ In our study, the SI isolates D1 and D2 from patient D were cytopathic to MT-2 cells. This correlates with a progression to a severe stage of disease in this patient.

Patient $\mathrm{E}$ was a child whose disease stage progressed during the study and died of AIDS with CD4 T cell counts dropping dramatically from 3015 to 171 . This suggests that the patient's virus was cytopathic in vivo. However, all isolates of patient $\mathrm{E}$ were NSI in phenotype. Taken together, this suggests that the syncytium-inducing ability of the viral isolates may not be directly responsible for HIV cytopathicity and in vivo CD4 T cell depletion may result from another mechanism.

The phenotypes of isolates from patient $F$ correlated with the individual's disease stage, whereas the phenotypes of isolates from patient $\mathrm{E}$ did not correlate with disease stage. Hence, NSI-SI phenotype may not always predict the clinical status or the progression of disease in infected individuals, especially infants. ${ }^{22}$ Cellular/viral factors that are intricately involved in the viral life cycle of HIV-1 may play a larger role in the cytopathic effects of HIV-1 regardless of the syncytium-inducing abilities of the viruses.

The biological phenotype described in this article for pediatric NSI isolates (ability to replicate in MT-2 cells) has also been observed with adult NSI isolates (unpublished results), suggesting that this NSI phenotype is not restricted to the pediatric population. Vavro et al. have also reported replication in MT-2 cells of NSI viruses from pediatric patients. ${ }^{23}$ Preliminary results in MT- 2 cells infected with adult and pediatric viral NSI isolates indicate differences in the kinetics of virus production, especially at early time points postinfection. Further investigation is underway to identify the factors that determine the rate of viral replication in cells and mechanism(s) of cytopathic effect. Patient isolates such as those described in this article will become useful tools in studies of HIV-1 induced cytopathogenicity.

\section{ACKNOWLEDGMENTS}

We thank Dr. Katherine Luzuriaga for her informative discussions. We thank Drs. Gregory Viglianti and Ruth-Anne Hesselton, and Frank Brewster, for their critical review of this manuscript. S.E.F. is supported by NIH Training Grant A107349-06. This work was supported in part by NIH grants (HL-42257 and AI-32907) and an NIH contract (HB-67022).

\section{REFERENCES}

1. Fauci AS: The human immunodeficiency virus: Infectivity and mechanisms of pathogenesis. Science 1988;239:617-622.

2. Lang W, Perkins H, Anderson RE, Royce R, Jewelle N, and Winkelstein W Jr: Patterns of T lymphocyte changes with human immunodeficiency virus infection: From seroconversion to the development of AIDS. J Acquir Immune Defic Syndr 1989;2:63-69.

3. Schellekens PT, Tersmette M, Roos MTT, Koot RO, De Wolf F, Coutinborand RA, and Miedema F: Biphasic rate of CD4+ cell count decline during progression to AIDS correlates with HIV-1 phenotype. AIDS 1992;6:665-670.

4. Sodroski J, Goh WC, Rosen C, Dayton A, Terwilliger E, and Haseltine WA: Role of the HTLV-III/LAV envelope in syncytium formation and cytopathicity. Nature (London) 1986;322:470-474.

5. Laurent-Crawford AG, Krust B, Muller S, Rivire Y, Rey-Cuille MA, Becht JM, Montagnier L, and Hovanessian AG: The cytopathic effect of HIV is associated with apoptosis. Virology 1991;189:695-714.

6. Somasundaran M and Robinson HL: A major mechanism of human immunodeficiency virus-induced cell killing does not involve cell fusion. J Virol 1987;61:3114 3119.

7. Ho DD, Moudgil T, and Alam M: Quantitation of human immunodeficiency virus type 1 in the blood of infected persons. N Engl J Med 1989;321:1621-1625.

8. Tersmette M, Lange JMA, de Goede REY, De Wolf F, EetinkSchattenkerk JKM, Schellekens P Th A, Coutinho RA, Huisman H, Goudsmit J, and Miedema F: Association between biological properties of human immunodeficiency virus variants and risk for AIDS and AIDS mortality. Lancet 1989;1:983-985.

9. Koot M, Vos AHV, Keet RPM, de Goede RY, Dercksen MW, Terpstra FG, Coutinho RA, Miedema F, and Tersmette M: HIV-1 biological phenotype in long-term infected individuals evaluated with an MT-2 cocultivation assay. AIDS 1991;6:49-54.

10. Tersmette M, Gruters RA, De Wolf F, de Goede RY, Lange JMA, Schellekens PT, Goudsmti J, Huisman HG, and Miedema F: Evidence for a role of virulent human immunodeficiency virus (HIV) variants in the pathogenesis of acquired immune deficiency syndrome: Studies on sequential HIV isolates. J Virol 1989;63:2118-2125.

11. Koot M, Keet RPM, Vos AHV, de Goede RY, Roos M Th L, Coutinho RA, Miedema F, Schellekens P Th A, and Tersmette M: Prognostic value of HIV-1 syncytium-inducing phenotype for rate of CD4+ cell depletion and progression to AIDS. Ann Intern Med 1993;118:681-688.

12. Richman DD and Bozzette SA: The impact of the syncytiuminducing phenotype of human immunodeficiency virus on disease progression. J Infect Dis 1994;169:968-974.

13. Tersmette $M$ and Miedema F: Interactions between HIV and the host immune system in the pathogenesis of AIDS. AIDS 1990;5:S57-66.

14. Roos MTL, Lange JMA, de Goede RY, Coutinho RA, Schellekens PTA, Miedema F, and Tersmette M: Viral phenotype and immune response in primary human immunodeficiency virus type 1 infection. J Infect Dis 1992;165:427-432.

15. Zhu T, Mo H, Wang N Nam DS, Cao Y, Koup RA, and Ho DD: Genotypic and phenotypic characterization of HIV-1 in patients with primary infection. Science 1993;261:1179-1181.

16. Fenyo EM and Asjo AJ: Replicative capacity, cytopathic effect and cell tropism of HIV. AIDS 1989;3:S5-12.

17. Hollinger FB, Bremer JW, Myers LE, Gold JWM, and the NIH/ NIAID/DAIDS/ACTG Virology Laboratories: Standardization of sensitive human immunodeficiency virus: Coculture procedures and establishment of a multicenter quality assurance program for the AIDS Clinical Trials Group. J Clin Microbiol 1992;30:1787-1794. 
18. Japour AJ, Mayers DL, Johnson VA, Kuritzkes DR, Beckett LA, Arduino JA, Lane J, Black RJ, Reichelderfer PS, D'Aquila RT, Crumpacker CS, the RV-43 Study Group, and the AIDS Clinical Trials Group Virology Committee Resistance Working Group: A standardized peripheral mononuclear cell culture assay for the determination of drug susceptibilities of clinical human immunodeficiency virus type 1 isolates. Antimicrob Agents Chemother 1993;37:1095-1101.

19. HIV syncytium-inducing (MT-2) assay. In: ACTG Virology Manual for HIV Laboratories, version 2.1. Hollinger FB (Ed.). Division of AIDS, NIAID, Bethesda, Maryland, 1993, pp. SIA-1-SIA-3.

20. Folks TM, Powell D, Lightfoote M, Koenig S, Fauci AS, Benn S, Rabson A, Daugherty D, Gendelman HE, Hoggan MD, Venkatesan S, and Martin MA: Biological and biochemical characterization of a cloned Leu- $3^{-}$cell surviving infection with the acquired immune deficiency syndrome retrovirus. J Exp Med 1986;164:280-290.

21. Singer RH, Byron KS, Lawrence JB, and Sullivan JL: Detection of
HIV-1 infected cells from patients using non-isotopic in situ hybridization. Blood 1989;74:2295-2301.

22. Terry Spencer L, Ogino MT, Danker WM, and Spector SA: Clinical significance of human immunodeficiency virus type 1 phenotypes in infected children. J Infect Dis 1994;169:491-495.

23. Vavro CL, Slade D, Valentine M, McKinney RE, and St. Clair M: A novel in vitro HIV property identified in pediatric patient isolates. (Session 89:294). 33rd Interscience Conference on Antimicrobial Agents and Chemotherapy, New Orleans, LA, 1993. [Abstract]

Address reprint requests to: Mohan Somasundaran Department of Pediatrics Program in Molecular Medicine University of Massachusetts Medical School 373 Plantation Street Worcester, Massachusetts 01605 